\title{
Gebelerin Gebelik Dönemine ve Doğuma İlişkin Mitlerinin Belirlenmesi
}

\author{
Determination of Myths Regarding The Pregnancy Period and Childbirth of Pregnant Women
}

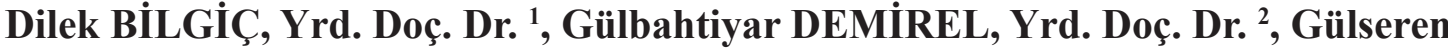 \\ DAĞLAR, Yrd. Doç. Dr. ${ }^{2}$
}

1. Dokuz Eylül Üniversitesi Hemşirelik Fakültesi, İzmir, Türkiye

2. Cumhuriyet Üniversitesi Sağlık Bilimleri Fakültesi Ebelik Bölümü, Sivas, Türkiye

$\ddot{O Z E T}$

Amaç: Gebelerin gebelik dönemine ve doğuma ilişkin mitlerinin belirlenmesidir.

Yöntem ve Gereçler: Tanımlayıcı tipteki araștırmanın örneklemini 24 Haziran - 30 Kasım 2013 tarihleri arasinda bir hastanenin kadın doğum polikliniğe başvuran ve araștırmaya katılmayı kabul eden 368 gebe oluşturdu. Veriler katılımo bilgi formu ve literatür doğrultusunda hazırlanan gebelik ve doğuma iliskin mit ifadelerinden olusan formun gebelere yüz yüze görüssme yöntemiyle toplandl. Verilerin değerlendirilmesinde ortalama, standart sapma, yüzde kullanıldi. Istatistiksel anlamlılık $p<0,05$ olarak kabul edildi.

Bulgular: Çalıșmamızda gebelerin yaș ortalaması 27.02 \pm 6.16 yıl olarak belirlendi. Gebelerin gebelik dönemine ilişkin en fazla dikkati ceken gebelikte cinsellikle ilgili ve bulantt-kusmava iliş̧kin mitler olurken doğuma iliş̧kin en fazla doğum ağrisıyla bağlantılı ve beslenmeye ilişkin mitler daha yüksek orandaydl.

Sonuç: Anne dostu kavramının gündemde olduğu günümüzde gebelerin gebelik dönemine ve doğuma ilișkin mitleri yaygınd. Bu anlamda gebelik ve doğum sürecine ilişkin mitlerin ortadan kaldırılmasi için gebelerin bilgilendirilmesi ya da gebe bilgilendirme sınıflarına, gebe eğitim sınıflarına katılmaları teşvik edilmelidir

Anahtar Kelimeler: mit, gebelik, doğum, cinsellik, beslenme

\section{ABSTRACT}

Objective: To describe the myths related to pregnancy and childbirth of pregnant women.

Material and Methods: The sample of this descriptive study 368 pregnant attending outpatient clinic of the obstetrics department of a hospital between 24 June and 30 November 2013 and accepting to participate in study were included. Questionnaire myths related to pregnancy and childbirth and participant information form prepared by the researchers, and was used to collect data and conducted face-to-face. Data were analyzed with arithmetic average, standard deviation, percentage distributions. Statistical significance was $p<0.05$ was accepted.

Results: The average age of the pregnant women in the our study was $27.02 \pm 6.16$ years. Pregnant women' myths the most prominent related to pregnancy were myths about sexuality and nausea-vomiting in pregnancy. As to the myths abouth the birth, associated with birth pain and myths for nutrition were higher rate.

\section{Iletişim Bilgileri}

Sorumlu Yazar: Gülseren DAĞLAR, Yrd. Doç. Dr.

Yazışma Adresi: Cumhuriyet Üniversitesi Sağlık Bilimleri Fakültesi Ebelik Bölümü, Sivas, Türkiye

E-posta: gulserendaglar@gmail.com

Tel: +90 (346) 2191258

Makale Geliş Tarihi: 07.11.2017

Makale Kabul Tarihi: 04.12.2017

DOI: http://dx.doi.org/10.16948/zktipb.349829
Conclusion: Nowadays that maternal-friendly hospital concept is remain on the agenda, myths related to pregnancy and childbirth of pregnant women is more. In this sense to eliminate wrong or negative myths about pregnancy and birth, pregnant women should be informed or in pregnancy information classes or participation in pregnancy training classes should be encouraged.

Keywords: myth, pregnancy, birth, sexuality, nutrition

\section{GİRIŞ}

Birçok toplumda, farklı sosyal sınıflar içerisinde gebelik ve doğum periyotlarının algılanma biçimi, kadının toplumdaki statüsü, ekonomi, eğitim, yaşam biçimi, tabular, dini inançlar ve mitler gibi faktörlerden etkilenmektedir $[1,2]$. Kültürümüzde de gebelik ve doğuma yönelik gelenek, görenek, örf ve âdetlerin yanı sıra halk inanışları da geniş bir yer tutar. Bunlar her ne kadar kulaktan dolma olup bilimsel bir temeli olmayan varsayımlar olsa da birçoğu halk arasında hâlâ doğru bildiğimiz yanlıșlar (mit) olarak geçerliliğini korumaktadır. Gebelik ve doğuma ilişkin mitlerin varlığı gebenin ve ailesinin olumsuz etkilenmesine neden olabilirken bazılar1nın hiçbir etkisi olmayabilir [3]. Gebelik ve doğum sürecine ilişkin bireyin, ailenin ve toplumun sahip olduğu inanışların ve mitlerin bilinmesi, bu mitlerin gebelik ve doğum süreci üzerine etkilerinin değerlendirilmesi, olumsuz etkilere neden olan mitlerin ortadan kaldırılması perinatal dönemin sağlıklı geçirilmesine katk1 sağlayacaktır. 21. yüzyılın sağlık dünyasında sağlık profesyonelleri için (doktor, ebe hemșire) gebelik, doğum ve sonrasında anne ve bebek sağlığının sürdürülmesinde kültürel yetkinlik esastır [4].

Ülkemizde toplumsal düzeyde gebelik, doğum, doğum sonrası ve bebek bakımına ilişkin geleneksel inanç ve uygulamalara yönelik çalıșmaların doğum sonrası kadınlarla ya da ileri yaştaki kadınların bu konuda sorgulanmasıyla gerçekleștirildiği görülmektedir [5,6]. Gebelerin gebelik ve doğuma ilişkin mitlerinin gebelik döneminde saptanması gebelik öncesinde ve gebelik döneminde mitler ve etkileri hakkında gebe ve ailenin bilgilendirilmesi gebenin, fetüsün ve ailenin sağlığına katkı sağlaması açısından önemli olacaktır.

Araştırmanın amacı, gebelerin gebelik ve doğuma ilişkin mitlerinin belirlenmesidir. 


\section{GEREÇ ve YÖNTEM}

Araştırma tanımlayıcı olarak yapıldı. Araştırmanın evrenini bir hastanenin kadın doğum polikliniğine başvuran gebeler, örneklemi ise 24 Haziran - 30 Kasım 2013 tarihleri arasında polikliniğe başvuran ve araştırmaya katılmayı kabul eden 368 gebe oluşturdu. Araştırmanın verileri literatür doğrultusunda geliştirilen Tanıtıcı Bilgi Formu ve Gebelik ve doğuma yönelik mitler formu yüz yüze görüşme yöntemi ile toplanmıştır. Tanıtıcı bilgi formunda gebelerin sosyodemografik özelliklerine (yaş, eğitim durumu, çalışma durumu, aile yapısı vb.), obstetrik özelliklerine ve mitler konusunda bilgi alma durumuna ilişkin toplam 22 soru yer almaktadır. Gebelik ve doğuma yönelik mitler formu, literatür bilgisi doğrultusunda hazırlanmış gebelik dönemine (cinsiyet tayini, beslenme, cinsellik) ve doğuma yönelik toplam 58 mit sorusundan oluşmuştur. Formların uygulanması ortalama 20 dakika sürmüştür. Elde edilen veriler bilgisayarda SPSS (14.0) paket programı kullanarak değerlendirilmiş verilerin değerlendirilmesinde veri dağılımlarının karşılaştırılmasında ortalama, standart sapma, yüzde değerler kullanılmıştır.

Tablo 1: Gebelerin Bazı Sosyo-Demografik ve Obstetrik Özelliklerinin Dağılımi ( $\mathrm{n}=368)$.

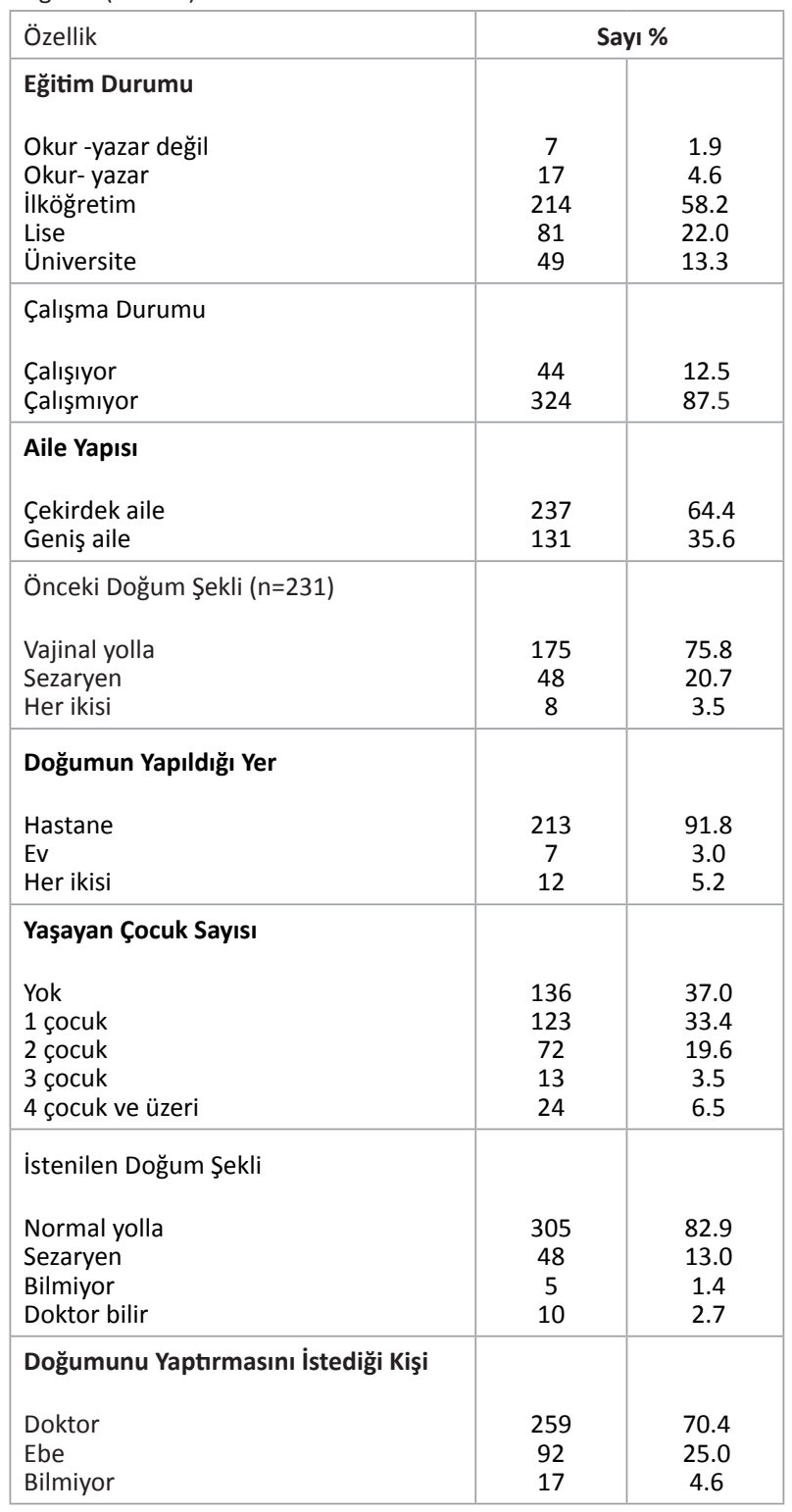

\section{BULGULAR}

Araştırmaya 16-51 yaşları arasında yaş ortalamas1 $27.0 \pm 6.16$ olan 368 gebe katıld1. Gebelerin ortalama gebelik haftas1 $31.5 \pm 9.28$ (min:5 max:42), gebelik sayıs1 $2.1 \pm 1.03$ (min:1 max:4) ve doğum say1s1 1.1 \pm 1.17 (min:0 max:4) olarak saptand1. Gebelerin sadece \%1,9'u okuryazar değildi, \%58,2'si ilköğretim mezunuydu, \%87,5'i ev hanımı ve $\% 64,4$ 'ü çekirdek aile yapısına sahipti. Araştırma kapsamına alınan gebelerin; \%75.8'i doğumlarını vajinal yolla, \%91.8'i hastanede yapmıştır.

Gebelerin \%37'sinin yaşayan çocuğu bulunmamaktadır. Gebelerin \%82,9'u şuandaki doğumu normal vajinal yol ile yapmak isteğini ve \%70.4'ü doğumunu doktorun yaptırmasını istediğini belirtmiştir (Tablo 1). Gebelerin sosyodemografik ve obstetrik özellikleri Tablo 1'de verilmiştir. Araştırmaya katılan gebelerin $\% 75.5$ 'i gebelik ve doğuma ilişkin bilgi sahibi olmadığını ifade etmiştir.

\section{Gebelerin gebelik ve doğuma ilişkin mitleri}

Gebelerin gebelikle ilgili en yaygın; \%91 oranında "Gebelikte ağlamak ve üzülmek kötüdür, bebek etkilenir"; \%88 oranında Gebelikte perde asmak, uzanmak, ağır bir şey kaldırmak gibi uygulamalar kesinlikle düşüğe yol açar" şeklinde mitlere sahip olduğu saptandı. Beslenmeye ilişkin en yaygın mitlerin \%83,2 oranında "Gebelikte aşeren kadına özlemini duyduğu her şey yedirilir"; \%60,8 oranında "Obez olan (çok şişman) gebeler sağlıklı bebek sahibi olamazlar" mitlerinin olduğu görüldü.

Gebelikte cinsellikle ilgili olarak; sırasıyla en yaygin \% 95,1 oranında "Gebelikte cinsellik olmamal1dır, bebeğe zarar verir." \%73,1 oranıyla "Gebelikte cinsel ilişkide bulunmak doğumu tetikler" \%71,2 oranında "Gebelikte orgazm olmak düşük ve erken doğuma neden olur" \%58,2 ile "Gebelikte cinsellik yaşanmamalıdır, bebek rahatsız olur" ve $\% 53,5$ ile "Gebelik döneminde cinsel istek duyulmaz" gibi mitlere inandıkları belirlendi. Gebelikte cinsiyet tahminine ilişkin olarak ise gebelerin $\% 56,2$ 'si "Gebenin karnı büyükse erkek, kalçası büyükse kız olur"; \%52,7'si "Kadın gebeliğgi sırasında güzelleşmişse oğlan doğuracak demektir"; ve \%51,1'i "Gebelikte göbek çizgisi koyulaşırsa erkek olur" gibi mitlere inanmaktaydilar (Tablo 2).

Doğuma ilişkin olarak ise gebelerin en fazla sırasıyla \%97,8 oranında "Doğum her zaman çok acı vericidir"; \%92,9 ile "Hastane, bir bebeğin doğumu için en rahat yerdir"; \%81,5 ile "Doğumu başarmak için yüksek düzeyde ağrıya dayanıklı olmak gerekir"; \%77,8 ile "Doğuma yardımc1 olacak tek şey ilaçtır "; \% 75,8 ile "Doğuma giden kadın o gün içinde hiçbir şey yiyip-içemez"; ve \%74,5 ile "İkinci ve sonraki doğumlar her zaman daha kolay olur" gibi mitlere sahip olduğu görüldü (Tablo 2).

Gebelerin gebelik ve doğum mitlerine yönelik görüşlerine Tablo 2'de yer verilmiştir. 


\section{TARTIȘMA}

Bilim ve teknolojideki gelișmeler gebelik ve doğuma yönelik yanlış inançları/mitleri bir dereceye kadar aşmamıza yardımcı olabilse de hala çoğuna inanılmaya devam edilmektedir (4). Bu çalışmada gebeyi etkileyebileceği düşünülen gebelikte cinsellikle ilgili sirasıyla \%95,1 "Gebelikte cinsellik olmamalıdır, bebeğe zarar verir"; \%73,1 "Gebelikte cinsel ilişkide bulunmak doğumu tetikler”; \%71,2 "Gebelikte orgazm olmak düşük ve erken doğuma neden olur"; \%58,2 "Gebelikte cinsellik yaşanmamalıdır, bebek rahatsız olur" ve \%53,5 "Gebelik döneminde cinsel istek duyulmaz" beslenme "Gebelikte aşeren kadına özlemini duyduğu her şey yedirilir"; ve yakınmalara "Gebelikte mutlaka sabah bulantıları olur”, ilişkin mitler yaygındı.

Doğuma yönelik ise gebe ve ailesinin doğum alg1s1nı doğuma katılımını önemli düzeyde etkileyebileceği düşünülen "Doğum her zaman çok acı vericidir"; Doğumu başarmak için yüksek düzeyde ağrıya dayanıklı olmak gerekir"; "Doğuma yardımcı olacak tek şey ilaçtır", "Doğuma giden kadın o gün içinde hiçbir şey yiyip-içemez" gibi mitlerin daha yaygın ve önemli olduğu belirlendi.

Çiftler arasındaki cinsel davranışlar yaşam kalitesini büyük ölçüde etkileyebilir [7, 8]. Gebelikte ve doğum sonrasında cinsel ilişki sırasında daha az istek, cinsel uyarı ve memnuniyet gibi durumlar cinsel aktivitenin azalmasina neden olabilmekte, cinsel sorunlar ve eş ilişkilerinde çatışmalar yaşanabilmektedir bu duruma katkıda bulunan faktörlerden biride gebelikte cinselliğe ilişkin inançlar ve mitlerdir [712]. Çalışmamızda gebeler bu dönemdeki inandıkları mitler nedeniyle bebek beklemeye başladıklarından itibaren gebelik döneminde cinsel aktivitenin kesilmesi gerektiğine inanmaktadırlar (Tablo 2).

En yüksek oranda çalışmamızda gebeler "cinsel aktivitenin bebeğe zarar vereceği" mitine inanmaktayd1. Trutnovsky ve ark'nin (2006), Zahraee ve ark'nın (2002) ve Naim ve ark'nın (2000) çalışmasındaki bulgularda da kadınlar gebelikte cinsel aktivitenin bebeğe zarar vereceğine inanmaktadırlar [13-15]. Yapılan benzer bir çalışmada da Shojaa ve ark. (2009) gebelerin en yaygı̂n cinsel ilişkinin 'bebeğe zarar vereceği, inciteceği' mitine sahip oldukları saptanmıştır [11]. Bunun yanı sıra bazı çalışmalarda da çoğu kadın için, cinsel ilişki gebelik süresince güvenlidir, hatta teşvik edilmeli ve kadınlar amniyom kesesi aç1lıncaya kadar bunu yapmaya devam edebilmelidir [16, 17]. Literatürde ve baz1 ilgili kanıt temelli rehberlerde de herhangi bir riskli durum olmadığı sürece gebelikte cinsel aktivitenin normal olduğu, gebeliğin doğal bir parçası olduğu, sürdürülebilir olduğu ve güvenli olduğu vurgulanmaktadır [18-24]. Cinsellikte salgilanan sevgi ve mutluluk hormonları, gebenin ve bebeğin zaten ihtiyacı olan hormonlardır. Doğum kontrolü olmadan cinselliğin yaşanıyor olması da bazı çiftleri özel olarak rahatlatmaktadır. Sadece özel durumlarda ya da riskli durumda kadınlara cinsel aktivite konusunda danışmanlık verilmelidir. Onun dişında gebelikte cinsellik vardır ve hatta olmalıdır [25].
Çalışmamızda gebelikte cinsellik için en önemli bir başka iki mit "Gebelikte cinsel ilişkide bulunmak doğumu tetikler"; ve "Gebelikte orgazm olmak düşük ve erken doğuma neden olur" şeklindeydi. Shojaa ve ark. (2009) çalışmasında da benzer olarak kadınlar cinsel ilişkinin doğumu başlatacağına ve erken doğum eylemine neden olacağına inanıyordu [11]. Benzer başka çalışmalarda da hem gebelerin hem de babaların aynı mite inandıkları için [2628] cinsel aktivite siklıklarını azaltma yoluna gitmektedirler. Bu durumda çiftler gebelik döneminde bireysel tatminlerini ön plana çıkarmakta ve eşler mastürbasyon yaparak cinsel doyuma ulaşmaya çalişmaktadir [12].

Çalışmamızda önemli diğer bir mitte "Gebelik döneminde cinsel istek duyulmaz"dı. Shojaa ve ark. (2009) çalışmasında da kadınlar benzer olarak gebelikte cinsel istek duyulmadığından isteksiz cinsel ilişkinin yaşanmasının çiftler arasında soruna yol açtığını belirtmişlerdir [3]. Literatürde yapılan çalışmalarda da gebelikte cinsel istek olmaksızın yaşanan cinsel aktivitenin çiftler arasında negatif bir ilişkiye yol açtığ saptanmıştır [7, 9, 10, 13]. Gebelikte cinselliğe ilişkin mitler çiftlerin kendini sınırlamasına, cinsel ilişki sıklığında azalmaya, isteksizliğe, memnuniyetsizliğe yol açarak [29-31], kadının yaşam kalitesi ve benlik saygısını, çiftin kişilerarası ilişkisini olumsuz etkileyebilir ve dogum sonrasinda devam edebilen cinsel disfonksiyonun gelişimine katkıda bulunan faktörlerden biri olabilmektedir [31-33]. Çalışmamızda da cinselliğe ilişkin mitlerin gebelikte ve doğum sonrasında çiftlerde cinsel sorunlara yolaçma potansiyeli taşıması açısından önemli olduğu düşünülmektedir. Gebelikte cinsel aktivite, sağlık profesyonelleri arasında nadiren tartışılmaktadır, ancak çoğu kadın tartışılması gerektiğini düşünmekte ve bu konuda bilgi almak istemektedir [34-36]. Bu nedenle gebelikte cinselliğe ilişkin mitler araştırılmalı ve çiftlere kapsamlı danışmanlık ve eğitim yapılarak mitler düzeltilmeye çalışılmalıdır.

Birçok kadın ebeveynleri tarafından iletilen yanlış inanç ya da mitlerden kaynaklı olarak gebelikte yanlış beslenme bilgisine ve davranışlarına sahip olabilmektedir ve gebelikte beslenme anne ve fetüsün sağlık sonuçlarını etkileyebilir [37, 38].

Guggino ve ark'ın (2016) yaptıkları çalışmada gebelerin \%90'ınının gebelikte beslenme konusunda mitlere sahip olduklarını saptamışlardır [39]. Çalışmamızda beslenmeyle ilişkili en yaygın "Gebelikte aşeren kadına özlemini duyduğu her şey yedirilir" miti saptanmıştır. Gebelikte aşerme bazı besinlere ve içeceklere karşı aşırı istek duyma olarak bilinir [40]. Aşerme genelde zararsız gibi düşünülse de bazen besin değeri yüksek olan besinlere karş1, bazen de düşük olan besinlere karşı istek duyulabilmektedir $[41,42]$. Bu doğrultuda besin ögelerinin yetersiz alınması anne ve bebekte sağlık sorunlarına neden olabilir. Aşerme bazen besin olmayan maddelere (toprak, kireç, diş macunu, sigara külü vb.) karşı da olabilir ki bu durum genellikle yetersiz beslenen annelerde sıktır. Kadın toprak, kil, kireç yemeye eğilim gösterir. Bu durumda anemi gelişebilir. 
Tablo 2: Gebelik Dönemine ve Doğuma İlişkin Bazı Mitlerin Dağılımı (N=368).

\begin{tabular}{|c|c|c|c|c|}
\hline \multirow{2}{*}{$\begin{array}{l}\text { Gebelik Dönemine iliş̧kin Mitler } \\
\text { Gebelikte ağlamak ve üzülmek kötüdür, bebek etkilenir }\end{array}$} & \multicolumn{2}{|c|}{ Doğru $n \%$} & \multicolumn{2}{|c|}{ Yanlış $\mathbf{n} \%$} \\
\hline & 325 & 91,0 & 33 & 9,0 \\
\hline Gebelik bir çeşit hastalıktır çok dikkat etmek gerekir & 137 & 37,2 & 231 & 62,8 \\
\hline Gebelikte cinsellik olmamalıdır, bebek rahatsız olabilir & 214 & 58,2 & 154 & 41.8 \\
\hline Gebelikte cinsellik olmamalıdır, bebeğe zarar verir. & 350 & 95,1 & 18 & 4,9 \\
\hline Gebelikte cinsel ilişkide bulunmak doğumu tetikler & 269 & 73,1 & 99 & 26.9 \\
\hline Gebelik döneminde cinsel istek duyulmaz. & 197 & 53,5 & 171 & 46.5 \\
\hline Gebelikte orgazm olmak düşük ve erken doğuma neden olur & 262 & 71,2 & 106 & 28.8 \\
\hline Gebenin mide yanması başlamışsa bu durumda bebek saç çıkarmaya başlamıştır & 264 & 71,8 & 104 & 28,3 \\
\hline Gebelikte mide ekşimesi çok olursa bebeğin saçı çok olur & 240 & 65,3 & 128 & 34,8 \\
\hline Obez olan (çok şişman) gebeler sağlıklı bebek sahibi olamazlar & 224 & 60,8 & 144 & 39,1 \\
\hline Gebelikte vajinal muayene yapılması düşüğe yol açar. & 265 & 72,0 & 103 & 28,0 \\
\hline Gebelikte aşeren kadına özlemini duyduğu her şey yedirilir. & 306 & 83,2 & 62 & 16.8 \\
\hline Gebelikte perde asmak, uzanmak, ağır bir şey kaldırmak gibi uygulamalar düşüğe yol açar. & 324 & 88,0 & 44 & 12,0 \\
\hline Gebelikte unutkanlık başlar. & 229 & 62,2 & 139 & 37.8 \\
\hline Gebeyken sıcak banyo yapılmaz. & 207 & 56,2 & 161 & 43.8 \\
\hline Gebelikte mutlaka sabah bulantiları olur & 250 & 67,9 & 118 & 32.1 \\
\hline Gebelikte Cinsiyet Tahminine İlişkin Mitler & \multicolumn{2}{|c|}{ Doğru n \% } & \multicolumn{2}{|c|}{ Yanlış $\mathbf{n} \%$} \\
\hline Gebelikte bol tatlı gıdalar yenirse çocuk kız, ekşi gıdalar yenirse erkek olur. & 140 & 38,0 & 228 & 62,0 \\
\hline Gebenin yüzü sivilcelenirse bebek kız olacak demektir & 152 & 41,3 & 216 & 58,7 \\
\hline Kadın gebeliği sırasında güzelleşmişse oğlan doğuracak demektir. & 194 & 52,7 & 174 & 47.3 \\
\hline Kadının gebelikte karnı büyük ve yukarı da ise kız doğuracak demektir. & 175 & 47,6 & 193 & 52.4 \\
\hline Gebenin karnı büyükse erkek, kalçası büyükse kız olur & 207 & 56,2 & 161 & 43.8 \\
\hline Gebenin yüzü yuvarlak ve dolgun ise bebeğin cinsiyeti kız, yüzü dar ve uzun ise bebeğin cinsiyeti oğlan olur & 148 & 40,2 & 220 & 59,8 \\
\hline Gebenin meme ucu koyulaşırsa erkek olur & 178 & 48,4 & 190 & 51.6 \\
\hline Gebe çok uyursa kız olur & 172 & 46,7 & 196 & 53.3 \\
\hline Gebelikte göbek çizgisi koyulaşırsa erkek olur & 188 & 51,1 & 180 & 48,9 \\
\hline Doğuma ilişsin Mitler & \multicolumn{2}{|c|}{ Doğru $n \%$} & \multicolumn{2}{|c|}{ Yanlış $\mathbf{n} \%$} \\
\hline Doğum her zaman çok acı vericidir & 360 & 97,8 & 8 & 2,2 \\
\hline Doğumu başarmak için yüksek düzeyde ağrıya dayanıklı olmak gerekir & 300 & 81,5 & 60 & 18,5 \\
\hline Doğuma yardımcı olacak tek şey ilaçtır & 280 & 77,8 & 88 & 22,2 \\
\hline Su kesesi her zaman doğuma girmeden önce patlar. & 250 & 67,9 & 118 & 32,1 \\
\hline Gebe rahim ağzı açılmaya başlar başlamaz doğuma girer & 217 & 58,9 & 151 & 41,0 \\
\hline Baharatlı yiyecekler doğumu tetikler. & 191 & 51,9 & 177 & 48,1 \\
\hline Doğumu sadece doktor bilir ve doktor yaptırmalıdır & 173 & 47,0 & 195 & 53,0 \\
\hline Kadın doğumdayken mutlaka annesinden destek almalıdır. & 208 & 56,5 & 160 & 43,5 \\
\hline Hastane, bir bebeğin doğumu için en rahat yerdir. & 342 & 92,9 & 26 & 7,1 \\
\hline Bir kadının doğumu kendi annesinin doğum deneyimine benzer & 211 & 57,3 & 157 & 42,7 \\
\hline İkinci ve sonraki doğumlar her zaman daha kolay olur. & 274 & 74,5 & 94 & 25,5 \\
\hline Doğuma giden kadın o gün içinde hiçbir şey yiyip-içemez. & 279 & 75,8 & 89 & 24,2 \\
\hline Erkeğin doğumda hiç rolü yoktur, dışarıda beklemeli hatta doğum olduktan sonra gelmelidir. & 203 & 55,2 & 165 & 44.8 \\
\hline Normal doğumdan sonra cinsellik eskisi gibi olamaz & 154 & 41,9 & 214 & 58,1 \\
\hline
\end{tabular}

Diğer besin öğelerinin emilimi engellenir, parazitler görülebilir. Bu nedenle bu mit önemli bir mit olup gebe kadının tüketmediği besinlerin öğrenilerek ihtiyaç duyulan besin ögelerinin başka besinler yoluyla yerine konması sağlanmalıdır [43].

Çalışmamızda "Gebelikte mutlaka sabah bulantıları olur" miti yakınmalarla ilgili en yaygın mit olarak belirlendi. Bulantı ve kusma, erken gebelik döneminin en rahatsız edici belirtilerindendir ve çoğu gebeyi etkilemektedir. Son yıllardaki araştırmalar bulant1 ve kusmanın sadece patolojik bir sorun değil aynı zamanda psikososyal ve kültürel faktörlerden de etkilendiğini göstermektedirler [44]. Çalışmamızda da bu mit yaygındır ve bulantı kusmanın gebelikte görülmesinin normalleştirilmesi gebe kadının bu konuda yeterli bakım almasını engelleyebileceği gibi bulantı ve/veya kusma nedeniyle yeterli gida ve sivi alamama, kilo kaybi, dehidratasyon, beslenme bozuklukları, metabolik bozukluklar, günlük yaşam aktivitelerinde zorluk, psikososyal stres ve depresyon yaşanma olasılığını artırmaktadır [45].

Çalışmamızda gebelerin daha yaygın olarak doğumla ilişkili doğum ağrısına yönelik mitlerinin "Doğum her zaman çok acı vericidir"; Doğumu ba- 
şarmak için yüksek düzeyde ağrıya dayanıklı olmak gerekir" ağır bastığı görülmektedir. Ağr1 tolerans1 değişkendir ve doğum sınıflarında öğretilen pek çok beceri, kadınların doğum ağrısı da dahil olmak üzere herhangi bir ağrı ile baş edebilme yeteneklerini artırmaya yardımcı olur. Daha da önemlisi bir gebenin doğum ağrisıyla baş etmesinde en önemli gösterge ağrıya gösterdiği toleranstan ziyade onun baş edebilme gücüne duyacağı güvendir [46, 47].

Bu konudaki mitlerin gebede doğum korkusuna yol açarak, doğumun olumsuz algılanmasına ve doğuma katılımı olumsuz etkilemesi açısından son derece önemli olduğu düşünülmektedir. Yüksek düzeydeki doğum korkusu katekolamin düzeyini arttırıp kontraksiyonları baskılayarak, doğum süresini uzatarak müdahaleli ve komplikasyonlu doğuma ve olumsuz bir doğum deneyimi yaşanmasına yol açabilecektir.

Gebedeki doğum korkusu aynı zamanda fetüs ve yenidoğanı da olumsuz etkileyerek doğum sonrası anne bebek etkileşimini de olumsuz etkileyecektir [48]. Doğum korkusu yaşayan gebelerin genellikle normal doğum yerine sezaryen doğum tercih ettikleri çalışmalarla da gösterilmiştir.

Çalışmamızda doğuma yönelik diğer önemli bir mit "Doğuma yardımcı olacak tek şey ilaçtır" olarak saptanmıştır. İlaçlar gebenin doğum ağrısı ile baş etmesine yardımcı olsa da genellikle annenin beklemediği veya istemediği yan etkilere neden olabilir. Doğumda ağrı ile baş etmek için birçok tıbbi olmayan yol vardır. Örneğin, suya girmek, doula kullanmak gibi, doğumda non-farmakolojik yöntemlerin kullanımı gebenin ağrıyla baş etmesine yardımcı olabileceği gibi forseps ve sezaryen gibi diğer müdahalelere olan ihtiyacı da azaltır [46, 47].

Dolayısıyla doğum memnuniyetinin artması, anne-bebek ilişkisinin güçlenmesi, emzirm4enin olumlu etkilenmesi, doğum ağrısının, oksitosin kullanımının, komplikasyonlu doğumların ve sezaryen doğum oranlarının ve tercihlerinin azalması için gebelerde doğuma yönelik ağrıyla ilişkili mitlerin ve buna bağlı olarak ta doğum korkusunun ele alınarak baş etme yöntemlerinin kullanılması ve doğum ağrısının şiddetli olmayacağı inancının mutlaka ele alınarak danışmanlık verilmesi ve gebelerin desteklenmesi [47, 48] gebe okullarının, doğuma hazırlık sinıflarının ve anne dostu hastane uygulamalarının yaygınlaştırılması son derece önemlidir.

\section{SONUC}

Gebelerin gebelik döneminde cinsellik ve doğum ağrısına ilişkin mitleri daha fazladır. Gebelik ve doğum sürecine ilişkin bireyin, ailenin ve toplumun sahip olduğu inanışların ve mitlerin bilinmesi önemlidir. Bu mitlerin gebelik ve doğum süreci üzerine etkilerinin değerlendirilmesi, olumsuz etkilere neden olan mitlerin ortadan kaldırılması kanıta dayalı eğitim programlarının uygulanması sağlıklı bir cinsel yaşamın sürdürülmesinde ve perinatal dönemin sağlıklı geçirilmesine katkı sağlayacağı düşünülmektedir.

\section{KA Y N A KLAR}

1. Russell-Roberts E. The principles of midwifery care in a trancultural context. 2009. ttp://www.rcn.org.uk/development/learning/transcultural_health/transcultural/midwifery.

2. Ünal $F \&$ Şentürk EA. Kültür ve kadın sağlığı. Hemşirelik ve ebelikte kültürlerarası yaklaşım Sempozyumu. 9-11 Nisan 2009. Çanakkale. Sayfa: 136.

3. Shojaa $M$, Jouybari $L$ \& Sanagoo A. The sexual activity during pregnancy among a group of Iranian women. Arch Gynecol Obstet 2009; 279:353-356.

4. Choudhary R, Gothwal1 S, Nayan $S \&$ Meena BS. Common ritualistic myths during pregnancy in Northern India. International Journal of Contemporary Pediatrics 2017;4(5):1-4.

5. Yalçın H. Gebelik, doğum, lohusalık ve bebek bakımına iliskin geleneksel uygulamalar (karaman örneği), Çocuk Sağlığl ve Hastalıklart Dergisi 2012;55:19-31.

6. Işık MT, Akçınar $M \&$ Kadıoğlu S. Mersin ilinde gebelik, doğum ve loğusalık dönemlerinde anneye ve yenidoğana yönelik geleneksel uygulamalar. Uluslararasi Insan Bilimleri Dergisi 2010; 7(1):63-84.

7. Bartellas E, Grane J, Daley M, Bennett K\& Hutchens D. Sexuality and sexual activity in pregnancy. Br J Obstet Gynaecol 2000;107: 964-968.

8. World Health Organization. Sexual health: Working definitions. 2002. http://www.who.International/ reproductivehealth/gender/sexual_health.html

9. Naim $M \&$ Bhutto E. Sexuality during pregnancy in Pakistani women. J Pak Med Assoc 2000;50:38-44.

10. Fok WY, Chan LY \& Yuen PM. Sexual behavior and activity in Chinese pregnant women. Acta Obstet Gynecol Scand 2005;84:934938.

11. Shojaa M, Jouybari LM \& Sanagoo A. Common myths among a group of Iranian women concerning sexual relationships during pregnancy. Arch Med Sci 2009;5(2):229-232.

12. Ertem $G \&$ Sevil Ü. Gebeliğin cinselliğe etkisi. Dirim Tip Gazetesi 2010;85(1):40-47.

13. Trutnovsky G, Haas J, Lang U \& Petru E. Women's perception of sexuality during pregnancy and after birth. Aust NZ J Obstet Gynaecol 2006; 46: 282-287.

14. Zahraee H, Shafiee K, Bashardoost $N$, Reihany $M$ \& Jabery P. Study of the related factors in couples' sexual relationship during pregnancy. J Qazvin Univ Med Sci 2002;20:62-67.

15. Naim $M$ \& Bhutto E. Sexuality during pregnancy in Pakistani women. Pakistani J Pak Med Assoc 2000;50:38-44.

16. Jahanfar $S \&$ MollaeNezhad M. Sexual problems. Bezheh \& Salemi Inc, 2nd Edi, 2006; 51.

17. Sueiro E, Gayoso P, Perdiz C\& Doval JL. Sexuality and pregnancy. Atencion Primaria 1998; 22: 340-346.

18. Sex in pregnancy. https://www.nhs.uk/conditions/pregnancy-and-baby/pages/sex-in-pregnancy.aspx (Erişim tarihi: 24.10.2017).

19. Sex during and after pregnancy. https://www.webmd.com/baby/ guide/sex-and-pregnancy\#1 (Erişim tarihi:24.10.2017).

20. Female sexual function, dysfunction, and pregnancy: implications for practice. https://www.medscape.com/viewarticle/732989_5 (Erişim tarihi:24.10.2017).

21. Kontoyannis $M$, Katsetos $C \&$ Panagopoulos P. Sexual intercourse during pregnancy. Health Sclence Journal 2012;6(1):82-87.

22. Brown CS, Bradford, JB \& Link WF. Sex and Sexuality in Pregnancy. The Global Library of Women's Medicine. 2008. https:// www.glowm.com/section view/heading/Sex\%20and $\% 20$ Sexuality $\% 20$ in\%20Pregnancy/item/111 (Erişim tarihi: 25.10.2017).

23. By Mayo Clinic Staff. Sex during pregnancy: What's OK, what's not. https://www.mayoclinic.org/healthy-lifestyle/pregnancy-week-by-week/in-depth/sex-during-pregnancy/art-20045318 (Erişim tarihi: 25.10 .2017$)$ 
24. Jones $C$, Chan $C \&$ Farine D. Sex in pregnancy. CMAJ;2011;19,183(7):815-817.

25. The truth about Sex during pregnancy. http://www.babygaga. com/10-fears-and-truths-about-sex-during-pregnancy/ (Erişim tarihi:25.10.2017).

26. Eryilmaz $G$, Ege $E$ \& Zincir $H$. Factors effecting sexual life during pregnancy in eastern Turkey. Gynecol Obstet Invest 2004;57(2):103-108.

27. Nelson S. “Women's Sexuality”. Women's Sexual Health. In: Andrews G, Studd J, 3rded. Elsevier. 2005.p.3-13.

28. Serati M, Salvatore S, Siesto G, Cattoni E, Zanirato M, Khullar $V$ et al. Female sexual function during pregnancy and after childbirth. $J$ Sex Med 2010;7:2782-2790.

29. Aribi L, Ben Houidi A, Masmoudi R, Chaabane K, Guermazi $M \&$ Amami $O$. Female sexuality during pregnancy and postpartum: $A$ study of 80 Tunisian women. Tunis Med 2012;90:873-877.

30. Khamis MA, Mustafa MF, Mohamed SN \& Toson MM. Influence of gestational period on sexual behavior. J Egypt Public Health Assoc 2007;82:65-90

31. Shojaa $M$, Jouybari $L \&$ Sanagoo A. The sexual activity during pregnancy among a group of Iranian women. Arch Gynecol Obstet 2009:279:353-356

32. Erol B, Sanli O, Korkmaz D, Seyhan A, Akman T\& Kadioglu A. A cross-sectional study of female sexual function and dysfunction during pregnancy. J Sex Med 2007;4:1381-1387.

33. Johnson CE. Sexual health during pregnancy and the postpartum. J Sex Med 2011;8:1267-84; quiz 85-86.

34. Kumar R, Brant HA \& Robson KM. Childbearing and maternal sexuality: a prospective survey of 119 primiparae. J Psychosom Res 1981; 25: 373-83.

35. Glazener CM. Sexual function after childbirth: women's experience, persistent morbidity and lack of Professional recognition. Br J Obstet Gynaecol 1997; 104: 330-335.

36. Eryilmaz G, Ege E \& Zincir H. Factors affecting sexual life during pregnancy in Eastern Turkey. Gynecol Obstet Invest 2004;57:103108.
37. Berti C, Decsi T, Dykes F, Hermoso M, Koletzko B, Massari M, et al. Critical issues in setting micronutrient recommendations for pregnant women: an insight. Maternal and Child Nutrition 2010;2:5-22.

38. Ricci E, Chiaffarino F, Cipriani S, Malvezzi $M \&$ \& Parazzini F. Diet in pregnancy and risk of small for gestational age birth: results from a retrospective case-control study in Italy. Maternal and Child Nutrition 2010:6:297-305.

39. Guggino A, Barbero S, Valentina P, Elsa V, Marilena D \& Simona B. Myths about nutrition in pregnancy. Journal of Obstetrics and Gynaecology, 2016;36(7):964-965.

40. Murray SS, Mckınney ES \& Gorrle TM. Foundations of Maternal-Nevborn Nursing, Third Edition, W.B. Saunders Company, Philadelphia, Pennsylvania, 2002: pp.: 242-394.

41. Jewell D \& Young G. "Interventions for Nausea and Vomiting in Early Pregnancy”, Cochrane Database Syst Rev. 2003; 4, CD000145.

42. Nordin S, Broman DA. Olofsson JK \& Wulff M. “A longitudinal descriptive study of selfreported abnormal smell and taste perception in pregnant women", Chem Senses. 2004;29(5):391-402.

43. Şahin H, Ongan D, Inanç N, Başer M\& Mucuk S. Gebelerin inanislarl: besin seçimi bebeğin cinsiyetini ve fiziksel özelliklerini etkiler mi? Aile ve toplum Eğitim-Kültür ve Araştırma Dergisi. 2009;5(9):4151 .

44. Tzeng YL. Unraveling the myths about nausea and vomiting during pregnancy. Hu Li Za Zhi. 2004;51(3):89-93.

45. Jennings-Sanders A. A case study approach to hyperemesis gravidarum: home care implications. Home Healthc Nurse. 2009;27(6):347-51; quiz 352-353.

46. Labor Pain: Myths and Truth. https://birthingnaturally.net/labor-pain-myths-and-truth/2016 (Erişim tarihi:25.10.2017).

47. Ricon-Ferraz A, Guimaraes H, Areias C\& Tomé T. Myths about childbirth. https://www.thebump.com/a/labor-myths (Erişim tarihi:25.10.2017).

48. Çiçek $\ddot{O} \&$ Mete S. Sık karşılaşılan bir sorun: doğum korkusu. DEUHFED 2015,8 (4), 263-268. 